\title{
United Nations convention on the rights of persons with disabilities needs to be interpreted on the basis of scientific evidence regarding psychiatry
}

\section{A brief overview of the convention}

The UNCRPD is an international human rights treaty drafted in December 2006 and opened for signatures in March 2007, which was developed following a call from a global meeting of experts in 1987 who recommended that the UN General Assembly draft a convention on the elimination of discrimination against persons with disabilities [1]. It is aimed to "promote, protect and ensure the full and equal enjoyment of all human rights and fundamental freedoms by all persons with disabilities", to ensure respect for their dignity and to stimulate a paradigm shift in attitudes and approaches, such that these persons "from objects of charity, medical treatment and social protection" and finally are "subjects with rights, capable of claiming those rights and making decisions for their lives based on their free and informed consent as well as being active members of society".

Existing human rights conventions already had a considerable potential to promote and protect the rights of persons with disabilities but, unfortunately, did not have the expected impact. The CRPD does not create new rights but sets out the legal obligations on States to promote and protect the rights of persons with disabilities.

There are eight guiding principles of the UNCRPD:

1) Respect for inherent dignity, individual autonomy, and independence of persons;

2) Non-discrimination;

3) Full and effective participation and inclusion in society;

4) Respect for differences and acceptance of persons with disabilities as part of human diversity and humanity;

5) Equality of opportunity;

6) Accessibility;

7) Equality between men and women;

8) Respect for the evolving capacities of children with disabilities and respect for the right of children with disabilities to preserve their identities.

Globally, the Convention was one of the most quickly supported human rights instruments in history, signed by 160 states upon opening in 2007 and ratified by 175 states as of December 2017. Several countries expressed reservations to the Convention or made declarations to clearly state their interpretation of the
Convention [2]. Additionally, 92 countries have signed the Optional Protocol, that establishes a process for complaints regarding perceived violations of the Convention.

\section{Reflections on the convention}

The EPA joins other associations in commending the United Nations commitment to promote the rights of persons with disabilities, and in identifying mental health as a global priority. The EPA strongly supports the paradigm shift embracing the model of shared decision making.

\section{The role of the special rapporteur}

Special Rapporteurs are independent human rights experts appointed to report on human rights issues in a specific country or theme. They hold this honorary position, are not employed by the UN, and are not paid for his/her work. The intention is to allow this expert to express his/her view in an independent capacity without representation of a specific Government.

The Special Rapporteur for Health is responsible for monitoring the global situation surrounding the right to health, and identifying health trends, and to report these findings to the HRC.

Reflections on the report of the special rapporteur on the right of everyone to the enjoyment of the highest attainable standard of physical and mental health

This Report [3] was discussed at the HRC thirty-fifth session in June 2017.

We acknowledge and appreciate the Special Rapporteur bringing mental health into focus for healthcare globally. The perspective that "there is no health without mental health" is very welcomed. The EPA Executive Committee and Committee on Ethical Issues share many of the Report's perspectives and goals, such as encouraging non-coercive treatments, more research extending beyond biological aspects of medicine with a focus on prevention, service provisions and social aspects of mental health. We share the concerns of the special rapporteur for the lack of respect of human rights in some regions in all parts of the world, acknowledge that this unfortunately happens also in the context of mental healthcare, and firmly believe that these instances need to 
be brought to light. However, the EPA Executive Committee and Committee on Ethical Issues express great concern and disappointment surrounding the misleading and false portrayal of psychiatry in the Report, as well as the lack of any evidence or statistics supporting this opinion. The EPA Executive Committee and Committee on Ethical Issues deems unacceptable the negative image of psychiatric care presented by the Report when the Special Rapporteur inexplicably blames current psychiatric practice for global unmet mental healthcare needs.

In fact, psychiatrists around the world are working for promotion and prevention in mental health. It is expected that by $2020,80 \%$ of all WHO Member States will have at least two functioning national multi-sectoral mental health promotion and prevention programs [4]. The Report questions effective treatments evidenced by scientific research - yet provides no evidence to support this misleading opinion. This risks harming people.

In the Report, psychiatry is caricatured as marred by human rights violations, using narrow bio-medically based methods and driven by the pharmaceutical industry. Prescription of proven and effective psychotropic medications is misrepresented as a failure of the mental healthcare system, yet this evidence-free view fails to appreciate the beneficial effects medications, often combined with psychotherapy, provide for service-users. By ignoring the evidence of the effectiveness of psychotropic medications, this Report undermines the efforts of all mental health workers and risks families or individuals discontinuing effective and even life-saving treatments.

In this way, the Report encourages avoidance of treatment which may in itself push people with mental disorders back into the undesirable situation of non-consensual hospitalizations as the only remaining treatment option.

We attest that the psychiatric profession is not only a voice for biomedical treatment, but also a field that focuses on psychotherapy, psychosocial treatments, social rehabilitation, and mental health in the workplace, school and community [5,6]. The Report fails to acknowledge the positive life-changing impact of interventions from mental health professionals, and the mental health system.

It fails to distinguish between mental healthcare malpractice (as in other healthcare sectors), and real-life professional and clinical standards and practice. The EPA Board and Committee on Ethical Issues reject the false description of the biomedical approach as a source of neglect, abuse and coercion, and as the key factor explaining the current unsatisfactory status of mental healthcare.

The assertion that academic psychiatry has confined its research and training agenda to biomedical treatments ignores over ten thousand published clinical trials on non-medication interventions and is demonstrably false. Research, training and care in psychiatry are founded on integrated sociological, developmental, psychological, and neurobiological understanding of mental health and disability.

The Report, discussing the "Global burden of obstacles", effectively ignores the most important obstacle - namely inadequate government funding for mental health, in a context where this is often both inadequate, and disproportionately discriminates against those with mental health issues.

Psychiatry is involved in delivering not only individual treatments, but also in striving together with service-users and families for health and social care system improvements. Psychiatrists usually do not control economic and political decisions necessary for system improvements.

We agree that "population-based approaches to mental health promotion move health systems beyond individualized responses towards action on a range of structural barriers and inequalities (social determinants) that can negatively affect mental health", but do not believe that population-based and individualized mental healthcare should be seen as dichotomous. These two approaches are supportive and complementary.

The Report states that "immediate action is required to radically reduce medical coercion and facilitate the move towards an end to all forced psychiatric treatment and confinement". If taken literally, this assertion would endanger the well-being of many persons. Although most people with mental disorders are not disabled, there are cases in which their disorders cause severe harm to themselves or others, and impairment of decision-making ability makes people vulnerable to exploitation and self-neglect. We do not agree that, for example, a person wandering lost and poorly dressed into an icy winter night due to dementia or psychosis should be left to their fate if the only possible life-saving intervention involves gentle coercion.

Coercive treatment represents a last-resort exception to the model of shared decision making; and must always be subject to rigorous scrutiny and challenge. Its elimination without adequately-resourced, recovery-oriented non-coercive alternatives would cause harm to service-users and others.

The Report describes all long-term care facilities as incompatible with human rights, especially for individuals with disabilities. However, the Report fails to present any realistic alternative care arrangements for individuals living with conditions that limit autonomy and require long-term care, such as elderly people with dementia.

Psychiatry, using the scientific medical model of open transparent scrutiny and self-critical published peer-reviewed research, is constantly striving to improve the quality and effectiveness of mental healthcare, including prevention. Psychiatry is open and inclusive, not exclusive. Unfortunately, the misguided and misinformed opinion-while-ignoring-evidence approach towards psychiatry in this UN Report risks causing actual harm to service-users and families.

The EPA Executive Committee and Committee on Ethical Issues would welcome a focus by the UN Special Rapporteur on the lack of financial resources for prevention, treatment and rehabilitation of mental disorders.

\section{References}

[1] UN General Assembly, Convention on the Rights of Persons with Disabilities : resolution / adopted by the General Assembly, 24 January 2007, A/RES/61/106, available at: http://www.refworld.org/docid/45f973632.html. [Accessed 18 December 2017].

[2] UN Treaty Series, vol. 2515, p.3, available at: https://treaties.un.org/Pages/ ViewDetails.aspx?src=TREATY\&mtdsg_no=IV$15 \&$ chapter $=4 \&$ lang=_en\&clang=_en.

[3] Report of the Special Rapporteur on the right of everyone to the enjoyment of the highest attainable standard of physical and mental health" (A/HRC/35/21): thirty-fifth session of the United Nations (UN) Human Rights Council, 6-23, June 2017.

[4] World Health Organization. WHO Executive Summary - Mental Health Atlas 2014. Published 2015. Available at: http://www.who.int/mental_health/ evidence/atlas/executive_summary_en.pdf?ua=1.

[5] Gutiérrez-Colosía M.R., et al. Standard comparison of local mental health care systems in eight european countries. Epidemiol Psychiatr Sci 2017;(Sep):1-14

[6] Priebe S, et al. Mental health-care provision for marginalized groups across Europe: findings from the PROMO study. Eur J Public Health 2013;23(1): 97-103.

Members of the EPA Executive Committee Silvana Galderisi*

Department of Psychiatry, University of Campania "Luigi Vanvitelli", Naples, Italy

Philip Gorwood ${ }^{\mathrm{a}, \mathrm{b}}$

${ }^{a}$ Clinique des maladies mentales et de l'encéphale (CMME), hôpital Sainte-Anne, Université Paris-Descartes, Paris, France

${ }^{b}$ Centre de psychiatrie et neurosciences, Inserm U894, Paris, France 
Wolfgang Gaebel

Department of Psychiatry and Psychotherapy, Medical Faculty,

Heinrich-Heine-University, Dusseldorf, Germany

Tamas Kurimay ${ }^{\mathrm{a}, \mathrm{b}}$

${ }^{a}$ Department of Psychiatry, St. Janos Hospital, Budapest, Hungary

${ }^{b}$ Institute of Behaviour Sciences, Semmelweis University, Budapest, Hungary

Geert Dom ${ }^{\mathrm{a}, \mathrm{b}}$

${ }^{a}$ Collaborative Antwerp Psychiatric Research Institute, University of Antwerp, Antwerp, BE

${ }^{b}$ Psychiatric Centre Brothers Alexianen, Boechout, BE

Julian Beezhold

Hellesdon Hospital and Norwich Medical School, University of East Anglia, Norwich, UK

Members of the EPA Committee on Ethical Issues Danuta Wasserman ${ }^{\mathrm{a}, \mathrm{b}}$

${ }^{a}$ National Centre for Suicide Research and Prevention of Mental IllHealth (NASP), Karolinska Institutet, Stockholm, Sweden

${ }^{b}$ WHO Collaborating Centre for Training, Research and Methods Development in Suicide Prevention, Stockholm, Sweden

Sue Bailey

University Hospital of South Manchester NHS Foundation Trust,

Manchester, UK
Cecile Hanon ${ }^{\mathrm{a}, \mathrm{b}}$

${ }^{a}$ Regional Resource Center of Old Age Psychiatry, Corentin-Celton Hospital, Academic Hospital West Paris, AP-HP, Paris, France

${ }^{b}$ Paris Descartes University, Sorbonne Paris Cité, Paris, France

Andreas Heinz

Klinik für Psychiatrie und Psychotherapie, Charité - Universitätsmedizin Berlin, Berlin, Deutschland

Norman Sartorius

Association for the Improvement of Mental Health Programmes, 14 Chemin Colladon, 1209 Geneve, Switzerland

Rutger Jan van der Gaag

Department of Child and Adolescent Psychiatry, University Centre St. Radboud \& Karakter, University Medical Center, The Netherlands

Livia Vavrusova

Psychiatrická klinika SZU a UNB, Bratislava, Slovakia

Jan Wise

Central and North West London NHS Foundation Trust, Wiser Minds

Ltd, London, UK

* Corresponding author.

E-mail address: silvana.galderisi@gmail.com (S. Galderisi). 